\title{
Employee-referral Schemes and Discrimination Law
}

\section{Michael Connolly*}

\begin{abstract}
Employee referral schemes ('introduce a friend') are in common usage in recruitment. They carry a potential to discriminate by perpetuating an already unbalanced workforce (say, by gender and ethnicity). With this, or course, comes the risk of litigation and bad publicity, as well as any inherent inefficiencies associated with discrimination.
\end{abstract}

This paper is threefold. First, it examines the present state of the law. Second, it is based on a survey of employers who use these schemes. Third, it analyses the range of schemes (and any safeguards) found to be in use.

The scrutiny showed that, where the business is small and/or the recruitment rate via the scheme is low, there is little risk of unlawful discrimination. But there is a risk. As the numbers involved increased, seemingly small disparities can become significant and thus vulnerable to litigation. It also found that, although a range of safeguards against discrimination were employed, none monitored the existing racial/gender profiles involved, thus exposing the schemes to potential litigation.

The key safeguard is relatively inexpensive monitoring of the protected characteristics (gender, ethnicity etc.) of the workforce, the relevant labour market, the pool of applicants, and the recruitment rate (via the scheme). This will highlight any patterns and suggestions of discrimination, and will help identify the cause(s).

\section{Background}

Over the past few years, it has become apparent that employers increasingly are using employee-referral schemes for hiring staff. ${ }^{1}$ The schemes reward staff for introducing a 'friend' to fill a vacancy. The chief reasons, it seems, are either a need to fill a skills gap by casting the recruitment net as far and wide as possible, and to save costs of expensive recruitment agency fees; ${ }^{2}$ there are other 'soft' advantages (discussed below).

\footnotetext{
University of Surrey. I would like to thanks the Nuffield Foundation for funding this project, and Sana Ahmad who provided valuable assistance and research.

See e.g. S Bridge, 'The smarter ways to break into banking' Sunday Times (London 22 June 2008 $<$ http://business.timesonline.co.uk/tol/business/career_and_jobs/careers_in/careers in_bankin g_and_finance/article4185550.ece> accessed 25 June 2009; 'Signals of job market boost grow stronger' Daily Telegraph (London 10 Feb 2005) <http://www.telegraph.co.uk/finance/2905418/Signals-of-job-market-boost-growstronger.html $>$ accessed 25 June 2009; 'Recruitment, Retention and Turnover', Annual Survey Report 2006 CIPD (London 2006), p. 2.

2 See e.g. case study of Xansa in 'Recruitment, Retention and Turnover', Annual Survey Report 2006 CIPD (London 2006), 10. $C f$ where some employers claim that the recruitment fees are insignificant when candidates remain employed for several years. See below, 'The Defence of Objective Justification'.
} 
One characteristic of these schemes is that they have a tendency to reproduce the existing gender/racial profile of the workforce. And if this is unbalanced, by comparison say, with the existing catchment area, these schemes could operate to exclude minority groups and/or women.

This suggests that the schemes could be unlawful under discrimination law. In essence, unlawful indirect discrimination occurs when an employer's facially neutral criterion (e.g., applicants must be 6' tall) has an adverse impact on a protected group, and the employer cannot show the requirement serves a necessary business need ('objective justification'). It is not necessary for liability that the employer has a discriminatory intent.

However, until recently, such schemes were beyond the reach of the UK's discrimination legislation. Previously, an employer's facially neutral practice could be challenged as discriminatory only if it amounted to a 'requirement or condition', which was interpreted to mean an absolute barrier. ${ }^{3}$ This meant that employee referral schemes were beyond the reach of the legislation, because such schemes are most unlikely to 'absolutely bar' anyone from the job, as it is likely persons could apply through other means. However, recent amendments to the legislation have replaced the word phrase 'requirement or condition' with 'provision, criterion, or practice', which is broad enough to encompass employee-referral schemes.

The aim of this project was first, to examine the legal developments that carried the potential to affect this area, second, to discover a range of schemes (including any safeguards) being practiced, and third, analyse them for their potential to discriminate on racial and gender grounds. The matter was confined to sex and racial discrimination for the sake of simplicity on this initial investigation, and as it was anticipated those surveyed were likely to be most conscious of these 'first generation' grounds.

\section{Interviewing Process}

To discover the range of schemes in operation, the project identified a number of businesses openly using the schemes. It will be seen below, that a variable contributing to any discriminatory impact of a scheme is the size of the business. Thus, 12 businesses were sampled to represent small, medium, and large employers. ${ }^{4}$

All interviewees and businesses involved were afforded complete anonymity.

The choice of interviewees fulfils Moser and Carlton's ${ }^{5}$ necessary conditions for successful completion of interviews: accessibility, cognition, and motivation. Human Resource managers have access to the information required. They will also have an understanding of

\footnotetext{
${ }^{3}$ See e.g. Perera $v$ Civil Service Commission [1980] ICR 699 (CA).

${ }^{4}$ The Companies Act 2006 categorises 'small' as having no more than 50 employees, (s 382(3)) and 'medium' having no more than 250 (s.465(3)). The category of micro, small and medium-sized enterprises (SMEs) is made up of enterprises which employ fewer than 250 persons and which have an annual turnover not exceeding 50 million euro, and/or an annual balance sheet total not exceeding 43 million euro.' Extract of Article 2 of the Annex of Recommendation 2003/361/EC.

5 C, Moser and G. Kalton, (1983) Survey Methods in Social Investigation. London: Heinemann.
} 
their role as interviewee, either to provide a detailed description plus an opinion from the employer's perspective (HR manager), or to validate (by e.g. concerning or correcting) the description and provide an opinion from the worker's perspective. Employers were motivated to participate as the project provides potential benefits to both employer and worker; these could include, for example, efficiency improvements, ${ }^{6}$ opportunity of refinement, litigation avoidance, maintenance or enhancement of reputation, formal identification of nepotism, and reinforcement of a scheme's validity. This motivation is underpinned by participants being aware that all contributions will remain anonymous.

\section{Proposition}

The proposition is that using existing staff to recommend recruits will perpetuate, and sometimes exaggerate, the existing gender/racial profile of the workforce. This is because existing workers are more likely to recommend persons from their ethnic/gender group. For the purpose of this paper, a workforce is 'unbalanced', generally or by job level, if it does not reflect its corresponding labour market by gender and ethnicity. If a scheme perpetuates an unbalanced profile, or exaggerates a balanced one to become unbalanced, it is putting women and minorities at a disadvantage, as they will be under-represented in the selection pool. Unless a scheme is objectively justified on grounds other than gender or race, it is vulnerable to a claim of unlawful discrimination.

A worker's choice of whom to refer is likely to be dictated by two factors.

1. Who you know: Existing workers are more likely to know people of their own gender or ethnicity. The can be seen in Pel v Modgill, ${ }^{7}$ and Rowe $v$ General Motors, ${ }^{8}$ discussed below.

2. Other subjective decision-making: Those referring are least likely to be trained in good recruitment practice, and so may be most prone to subjective decision-making. Existing workers are more likely to recommend persons whom they consider would 'fit in'. This can operate in several ways. Their recommendations may be based on rather crude stereotypes: for instance, a heavy plant driver may assume only men could do the job, whilst a secretary may presume her job is only suited to women.

At a slightly more subtle level, referrers may assume certain characteristics ('soft skills') are essential for a particular job, and associate these characteristics with gender or ethnic/racial stereotypes: city traders require aggressiveness (male), managers require assertiveness (male), nurses should be maternal, retail customers prefer White sales staff, and so on. ${ }^{9}$ Thus, referrals could perpetuate patent and more subtle gender and racial stereotypes.

${ }^{6}$ For an extensive study of business efficiency and indirect discrimination law, see Greenberger, 'A Productivity approach to Disparate Impact and the Civil Rights Act of 1991.’ 72 Oregon Law Rev 253 (1993).

${ }^{7}$ FTATU v Modgill; Pel Ltd v Modgill [1980] IRLR 142 (EAT).

$8457 \mathrm{~F} 2 \mathrm{~d} 348$, at $358-359$ ( $5^{\text {th }}$ Cir 1972).

${ }^{9}$ The HR professionals are just as capable of deploying gender stereotypes: '[I]n one ... organisation that employed more male managers, managerial competencies included: stress tolerance, thriving on pressure, maintaining logic and persuasiveness of argument despite heavy opposition. In contrast managerial competencies in a retail environment that had a higher proportion of female managers, included: open door policy, taking an interest in employees' lives, having concern for wellbeing of individuals': C. Evans, J. Glover, Y. 
Referrers also may make cultural presumptions about their workplace: members of an allWhite decorating team may assume that a woman, or a recent Bangladeshi immigrant, would not fit in; an aggressive all-male sales team may consider that a woman would dilute the competitive and/or 'buddy' atmosphere of the office; an all-White office subconsciously may assume that a person of Chinese origin would not 'fit in', or 'be part of a small staff that could work well together as a team' because she did not come from the 'same, essentially British academic, background'. ${ }^{10}$

\section{Stratification}

Women and minorities may be under- or over-represented by gender or race in various strata of the workplace, defined by skills and/or seniority. Typically, management may be predominantly White and male, whereas women and racial minorities may be overrepresented in menial jobs: a 'bottom-heavy' profile. Here, it is likely that the senior/skilled workers will recommend White male candidates, whilst the menial workers will recommend female or racial minority candidates. In extreme cases this can lead to segregated workplaces, with say, Black workers occupying all the menial jobs. ${ }^{11}$

\section{The 'Unbalanced' workforce}

Normally, for a scheme to discriminate in this way, the workforce needs to be unbalanced in the first place. This prompts the question, what caused the imbalance before the scheme came into being? There can be several 'background' reasons for this. The most obvious causes would be a change in the demographics and skills-profile in the labour market. ${ }^{12}$ Take this example. A local authority's refuse collectors (low-skilled) are exclusively White, yet the corresponding labour market (most of the local population) is 20 per cent Black and 10 per cent Asian. The reason behind this that in the post-war years, the catchment area was also exclusively White, but began to change in the 1950's with immigration. In the meantime, the word-of-mouth hiring policy preserved the racial profile, which became unbalanced as the labour market changed. ${ }^{13}$

Even where demographics remain stable, the skills profile of the labour market may change. For instance, at one time fewer girls than boys entered further and higher education, ${ }^{14}$ leaving

Guerrier, C. Wilson, 'Effective recruitment strategies and practices: addressing skills needs and gender diversity challenges in ITEC and related sectors' (2007) Equalitec 2007), p.8.

$<$ www.equalitec.org.uk/downloads/Effective_recruitment_strategies_and_practices.pdf > accessed 25 June 2012.

${ }^{10}$ See King v Great Britain-China Centre [1992] ICR 516 (CA), p.524.

${ }^{11}$ See FTATU v Modgill; Pel Ltd v Modgill [1980] IRLR 142 (EAT), discussed below.

12 e.g. recent immigration in the catchment area, or increased skills among women and some second and third generation immigrants.

${ }^{13}$ See R. v Commission for Racial Equality ex p. Westminster CC [1984] I.C.R. 770 (QBD), p.778, affirmed in part [1985] ICR 827 (CA).

${ }^{14}$ See Price v CSC [1978] ICR 27 (EAT), at p.32; Birmingham City Council v EOC [1989] AC 1155 (HL), where fewer girls than boys could attend grammar schools. Nowadays, the trend is in reverse, with fewer boys achieving academically. In the 1930's, women constituted less than a quarter of the university student population, (C. Dyhouse, 'Students: A Gendered 
women underrepresented at particular skills levels. Where women were similarly underrepresented at skills levels in the workplace, the workforce profile would have been balanced, because it corresponded with the respective labour market. However, as an increasing proportion of women carry academic qualifications, the labour market changes, and unless the employer keeps up with this, its workforce profile will become unbalanced.

An unbalanced workforce profile could result also from discriminatory hiring from a time when it was lawful. ${ }^{15}$ The main sex and race discrimination legislation came into force in the mid-1970's, ${ }^{16}$ and so one might suppose that the lingering effects would have dwindled away some 35 years' on. However, passive word-of-mouth hiring remained lawful (and may well still be so). ${ }^{17}$ Thus, it is conceivable that that some workplaces remain unbalanced because word-of-mouth hiring perpetuated the profile.

\section{Testing the Proposition}

\section{The Law}

The Equality Act 2010 (EA 2010) outlaws discrimination in recruitment (s.39) whilst indirect discrimination is defined by s.19. Section 39 provides:

'(1) An employer (A) must not discriminate against a person (B)--

(a) in the arrangements A makes for deciding to whom to offer employment;

(b) as to the terms on which A offers B employment;

(c) by not offering B employment.'

Paragraph (a) covers all aspects of the recruitment process leading to the appointment and the terms of that appointment. This will include, for example, the drawing up of the job specification, taking up references, short-listing, and interviewing.

History', Routledge, Abingdon, 2006). By 2010, women made up 58.5 per cent of the (domiciled) student population: Higher Education Statistics Agency < http://www.hesa.ac.uk/index.php?option=com_content\&task=view\&id=2275\&Itemid=278 > accessed 11 July, 2012. Across the UK as a whole, in 1976, 18 per cent of boys and 16 per cent of girls left school with at least one 'A' Level or Higher. Girls overtook boys in the 1980's, and in 1991, the rate was 25 per cent for boys, and 29 per cent for girls. J. Powney, 'Education and Attainment' (Scottish Office Education and Industry Department 1996) ISBN 1860030319 , para.5.3.

${ }^{15}$ See e.g. in US, Griggs v Duke Power 401 US 424 (1971) and Rowe v General Motors 457 F 2d 348 ( $5^{\text {th }}$ Cir 1972), (below).

${ }^{16}$ Sex Discrimination Act 1975; Race Relations Act 1976.

${ }^{17}$ Based on the notion that an absence of a recruitment policy, which defaults to word-ofmoth hiring, is an 'act' and so not actionable. See Pel Ltd v Modgill [1980] IRLR 142 (EAT) (below), and M Connolly, Discrimination Law ( $2^{\text {nd }}$ edn Sweet and Maxwell: London, 2011), p.114. 
Word-of-mouth and employer-referral hiring should come within the 'arrangements'. Although this has not been tested in the courts, ${ }^{18}$ the Court of Appeal observed, obiter, in Coker v Lord Chancellor: ${ }^{19}$

'It is possible that a recruitment exercise conducted by word of mouth, by personal recommendation or by other informal recruitment method will constitute indirect discrimination .... If the arrangements made for the purpose of determining who should be offered employment or promotion involve the application of a requirement or condition to an applicant that he or she should be personally recommended by a member of the existing workforce that may, depending of course on all the facts, have the specified disproportionately adverse impact on one sex or on a particular ethnic group and so infringe [the legislation]. ${ }^{20}$

This suggests strongly that employee referral schemes come within the 'arrangements' under s.39(a).

Indirect discrimination is defined by the Equality Act 2010, s.19:

(1) A person (A) discriminates against another (B) if A applies to B a provision, criterion or practice which is discriminatory in relation to a relevant protected characteristic of B's.

(2) For the purposes of subsection (1), a provision, criterion or practice is discriminatory in relation to a relevant protected characteristic of B's if-

(a) A applies, or would apply, it to persons with whom B does not share the characteristic,

(b) it puts, or would put, persons with whom B shares the characteristic at a particular disadvantage when compared with persons with whom B does not share it,

(c) it puts, or would put, B at that disadvantage, and

(d) A cannot show it to be a proportionate means of achieving a legitimate aim.

The formula consists of the following elements: (1) an apparently neutral provision, criterion or practice, (2) which puts, or would put, ${ }^{21}$ (3) the claimant ${ }^{22}$ and the claimant's group at a 'particular disadvantage', and (4) cannot be justified (para.(d)). The first three complete the

${ }^{18}$ The US Circuits are divided on word-of-mouth hiring: see United States v Georgia Power $474 \mathrm{~F} 2 \mathrm{~d} 906$, at 925-926 ( $7^{\text {th }}$ Cir 1993) and EEOC v Chicago Miniature Lamp Works $947 \mathrm{~F}$ 2d 292 (7th Cir 1991).

19 [2002] I.C.R. 321 (CA).

${ }^{20}$ Ibid, [57].

${ }^{21}$ This allows for a person deterred by the provision, criterion, or practice: Explanatory Notes, para.79.

${ }^{22}$ This is merely to ensure a claimant has locus standi (a right to sue): see e.g. 893 Hansard HC 1491-2 18 June 1975. 
claimant's prima facie case, after which the burden shifts to the defendant to objectively justify the challenged practice.

For these cases, the referral scheme is the 'practice', which may 'disadvantage' a protected group, and if it does, the employer must justify the practice by showing it is an appropriate and necessary means of achieving a legitimate aim. Note here, that nothing in the definition requires a discriminatory motive by the employer. It is enough that the challenged practice (in this context, the referral scheme) has the adverse effect on the protected group. ${ }^{23}$

\section{From Unregulated Recruitment to Employee Referrals}

There is no evidence to date of a scheme discriminating on one of the prohibited grounds. The existing evidence relates to unregulated and word-of-mouth hiring (sometimes called 'subjective hiring practices'). Employee referral schemes generally are a sophisticated version of word-of-mouth hiring, and can share some of the more general features of subjective hiring practices.

\section{Unregulated Recruitment Generally}

The first theory is that unregulated recruitment will discriminate. This, of course, requires qualifying. Unregulated recruitment risks discrimination because it has a tendency to replicate or 'freeze' the existing workforce profile. We cannot assume that, without regulation, a workforce will replicate its own profile. In proportion to the catchment area, White workers may mix socially with all races, male workers may mix with a men and women, and so on. However, neither can we assume the opposite. Without regulation, there is always the risk that a workforce will replicate its own profile. The evidence supporting this begins with simple unregulated practices and graduates to employee referrals.

In the US case, Rowe $v$ General Motors, ${ }^{24}$ the following promotion/transfer procedure was identified:

(1) The foreman's recommendation was the indispensable single most important factor in the promotion process.

(2) Foremen were given no written instructions for the qualifications or qualities necessary for promotion.

(3) Those standards which were determined to be controlling were vague and subjective.

(4) Hourly employees were not notified of promotion opportunities nor were they notified of the qualifications necessary to get jobs.

\footnotetext{
${ }^{23}$ See the seminal case on indirect discrimination, Griggs v Duke Power 401 US 424 (1971), at p.432.

${ }^{24} 457 \mathrm{~F} 2 \mathrm{~d} 348$, at $358-359\left(5^{\text {th }}\right.$ Cir 1972).
} 
(5) There were no safeguards in the procedure designed to avert discriminatory practices.

The background to this case was a history of direct discrimination (prior to the Civil Rights Act 1964), which kept Black workers in the lower-paid hourly jobs. The evidence was that the informal promotion/transfer procedure tended to preserve this disparity. Here, the employer was found liable for indirect discrimination.

Rowe illustrates that unregulated recruitment can discriminate unlawfully by perpetuating existing stratified inequalities. Here the 'referral' was by the foreman and confined to internal transfers and promotions, rather than external hiring. A step closer to employee referral schemes is patent word-of-mouth hiring, the effects of which are demonstrated in the next two cases.

In Pel Ltd $v$ Modgill, ${ }^{25}$ the dirtiest work in the employer's factory was paint spraying. Originally, it was staffed by a mix of Black, White, Asian and 'African-Asian' workers. Over a 'few years', vacancies were filled by word of mouth, a practice exploited by the AfricanAsians (who shared a common language), ${ }^{26}$ who recommended their friends and family. This led to the paint shop being staffed entirely by African-Asians, whilst the rest of the factory remained mixed. ${ }^{27}$

A more explicit example can be seen in another US case, Montana Rail Link v Byard. ${ }^{28}$ Here, it was held that the following amounted to a discriminatory employment practice, as it tended to favour men, who dominated the workforce.

(1) A 'word-of-mouth' recruitment campaign was instigated by the employer.

(2) Those responsible for making hiring decisions followed no written instructions for to the qualifications necessary for hiring.

(3) The standards which were determined to be controlling were vague and subjective.

(4) The applicants were not properly informed, and indeed may have been misled about the qualifications necessary to get jobs and about the procedures they had to follow to be hired.

(5) There are no safeguards in the hiring procedure designed to avert discriminatory practice.

(6) The impression made on the interviewers by the applicants was the single most important factor in the hiring process, although the applicants were not told of this.

\footnotetext{
${ }^{25}$ FTATU v Modgill; Pel Ltd v Modgill [1980] IRLR 142 (EAT).

${ }^{26}$ Not English. Ibid, para.32.

${ }^{27}$ No claim of indirect discrimination was made. The EAT held that in the absence of policy to segregate, there was no unlawful segregation under RRA 1976, s.1(2)the Act (now EA 2010, s.13(5)).

${ }^{28} 260$ Mont 331, at 352 (1993). Decided under the Montana Human Rights Act under Title VII disparate impact principles.
} 
(7) Interviews for some applicants were no more than 'informal chats'.

(8) Some applicants were hired without an interview.

Meanwhile, the sparse statistics revealed that about 12 per cent of the largely low-skilled workforce was female, which did not of course reflect the gender profile of the pool of potential candidates. The combination of the unregulated word-of-mouth recruitment and the statistic were enough to prove indirect discrimination. There are, of course, many more examples. ${ }^{29}$

The cases have arisen in the United States principally because of the more open-ended legislation, requiring only an employment practice for liability, rather than an employment requirement - or 'absolute bar' - which was required until recently in the UK. ${ }^{30}$ Nonetheless, research conducted in the UK during late 1970's suggests that unregulated word-of-mouth recruitment reproduced the racial profile of the workplace, thus discriminating inter alia against recent immigrants. ${ }^{31}$ Accordingly, the original Code of Practice, for sex discrimination in employment, suggested that where it precludes members of one sex from applying, word-of-mouth recruitment should be 'avoided'.

These cases and research illustrate that unregulated word-of-mouth hiring risks perpetuating the workforce profile. Much depends on other factors. The most obvious being an existing

${ }^{29}$ See e.g. R. v Commission for Racial Equality ex p. Westminster CC [1984] I.C.R. 770 (QBD), p.778, affirmed in part [1985] ICR 827 (CA) (all-White refuge collectors recruited solely by word of mouth); R. Jenkins, 'Acceptability, Suitability and the Search for the Habituated Worker: How Ethnic Minorities and Women Lose Out', International Journal of Social Economics, (1993), Vol. 11 Iss: 7; in the US see EEOC v Chicago Miniature Lamp Works 947 F 2d 292 (7th Cir 1991), reversed only because the word-of-mouth, not instigated by the employer, hiring did amount to a 'practice' for the legislation.

${ }^{30}$ Perera v CSC [1983] ICR 699 (CA), discussed above, text to n.3.

31 G. Lee, and J. Wrench (1983) Skill Seekers - Black Youth, Apprenticeships and Disadvantage National Youth Bureau, Leicester. Conducted for The Commission For Racial Equality. Reported in J. Wrench And T. Modood, 'The Effectiveness Of Employment Equality Policies in Relation to Immigrants and Ethnic Minorities in the UK', International Migration Papers 38, International Labour Office Geneva, Para 2.1.3. < http://www.ilo.org/public/english/protection/migrant/download/imp/imp38.pdf $>$ (accessed 25 June 2012); Commission for Racial Equality, Reports of Two Formal Investigations: (I) F. Broomfield Ltd; (2) London Drivers Supplied Services Ltd., Employment Agency, London, CRE, 1980; For example: J. Chaney, Social networks and job information, Manchester, Equal Opportunities Commission, 1981; M.S. Grieco, 'Family Structure and Industrial Employment', Journal of Marriage and the Family, August 1982, pp. 701-707; H. Kahn, The Repercussions of Redundancy, London, Allen and Unwin, 1964; D.I. McKay, et al., Labour Markets Under Different Employment Conditions, London, Allen and Unwin, 1971; North Tyneside CDP, In and Out of Work, Newcastle, 1978.

${ }^{32}$ Originally issued by the Equal Opportunities Commission. The new EHRC Code of Practice on Employment makes no mention of word-of-mouth recruitment. See < http://www.equalityhumanrights.com/advice-and-guidance/information-for-advisers/equalityact-codes-of-practice/ > accessed 31 July 2012. 
unbalanced workforce profile. At its most blatant, this could be an all-White, or all-male, factory, city firm, or building site. More commonly, minorities and women might be underrepresented in the senior jobs, and over-represented in the lower-ranking ones. Fluidity of the 'catchment area' will also affect this. At one time, a workplace may reflect its catchment area, but recent immigration will change this. If the workforce profile is unbalanced, either because of previous discrimination, or recent immigration, or for any reason, then the perpetuation of that unbalanced profile suggests a case of indirect discrimination.

The principle driver in these cases is existing workers introducing their friends and family (and perhaps acquaintances) into the workplace. The same principle drives any employee referral scheme. So, it can be concluded from this that employee referral schemes risk perpetuating existing workforce profiles and in turn risk discrimination. Much depends on how regulated they are, which is discussed below ('Safeguards'). First, some basic legal parameters are required.

In the context of referral schemes, for a prima facie case of indirect discrimination, the following elements are required.

\section{1. (EA 2010, s.4) Claimant has a protected characteristic.}

Here, that would be gender or ethnicity.

\section{2. (EA 2010, s.39(1)(a)) Employer's 'arrangements' for recruitment.}

The referral scheme.

3. (EA 2010, s.19) A 'provision, criterion or practice'.

The referral scheme is a practice.

\section{The claimant's particular disadvantage}

Typically, the claimant's disadvantage is not knowing when vacancies arise, and so the loss of a job opportunity.

\section{The claimant's group-disadvantage}

It must be shown that a significantly greater proportion of the claimant's group has the disadvantage. This can be done in a number of ways: by showing that the scheme is intrinsically liable to disadvantage the group ${ }^{33}$ or that there is a considerable difference between the proportions, ${ }^{34}$ or that there is a small but persistent difference between the proportions. $^{35}$

6. Causation: The practice 'puts, or would put' the claimant and her/his group at a particular disadvantage.

${ }^{33}$ O'Flynn v Chief Adjudication Officer Case - C237/94, [1996] ECR I-2617 (ECJ). See also Case C-212/06 Government of the French Community v Flemish Government [2008] ECR I1683 (ECJ), [73].

${ }^{34}$ Seymour-Smith Case C-167/97, [1999] I.C.R. 447 (ECJ).

35 Seymour-Smith Case C-167/97, [1999] I.C.R. 447, [61]: A prima facie case can be established where "the statistical evidence revealed a lesser but persistent and relatively constant disparity over a long period." 
It must be shown that the scheme is the cause of the disparity. Among other things, this element ensures that employers, faced with an imbalanced workforce, are not driven to hire by quota.

In these cases, the logic is somewhat circular. The requirements for typical cases are an 'unbalanced' workforce and a significant recruitment rate via the scheme. This suggests that the imbalance is caused by the scheme. It is a negative cycle. Of course, where the recruitment rate is 100 per cent, this is straightforward. When it falls below that, things can become more nuanced.

As the recruitment rate drops, it will be harder to show that the scheme is the cause of the disparity. But this does not necessarily mean there is no discrimination. An unbalanced profile suggests there is discrimination somewhere in the recruitment process. Further investigation may reveal this. It might be that even though it accounts for small proportion of recruitment, a scheme is the main cause of the unbalanced profile. However, as the recruitment rate drops, and it becomes increasingly difficult to show causation, an argument that the scheme is not discriminatory simply condemns another part of the hiring process. If say, there is a significantly imbalanced workforce at a particular level, and only about five per cent are hired via the scheme, the next most likely explanation of the imbalanced workforce is discrimination elsewhere. It might be that the employer advertises only in White areas, or there is discrimination in the selection processes, say subjective decision-making and/or disproportionately White/male interview panels. This may not help the individual challenge to the scheme, but it would expose the employer's general hiring practice, which then would be open to challenge.

\section{Who sues?}

At first sight, it might be supposed that to sue the employer for indirect discrimination, a person must have applied for, and been rejected from, a job. As the nature of this problem is that applicants do not know of the vacancies, this is an unlikely scenario. However, there are other possibilities to challenge discriminatory referral schemes.

A person from a protected group disadvantaged by the scheme may discover the existence of the scheme (say by an overheard conversation in a cafe), but knows nobody who works for the business. This person may not hear when vacancies arise, and so is disadvantaged by the practice, fulfilling the locus standi requirement of s.19. It is possible for this person to be an existing worker, 'locked into' a lower status job, but less likely to discover when vacancies arise at more senior levels. This could be, for instance, a Black cleaner qualified for a semiskilled post, at a level where Blacks are under-represented.

\section{The ‘White Male’ Victim}

A counter-intuitive but logical claim could arise here where the unbalanced profile is confined to the least desirable jobs in a business (e.g. unskilled cleaning jobs). Suppose that Asians were over-represented in these jobs. Here a White person could complain of being 'frozen out' of the cleaning jobs, especially if there is high unemployment and so even these jobs are 'desirable'. A tribunal ordering the employer to abandon the scheme ${ }^{36}$ effectively

${ }^{36}$ EA 2010, s.124. See below, 'Remedies'. 
would be ordering it to employ fewer Asians and more Whites. This logic also applies where women are over-represented in less desirable jobs.

The underlying problem here is that it is less likely that an individual claim could address the 'bottom-heavy' profile of a stratified workforce. However, there are two ways by which a stratified imbalance as a whole could be challenged. The first is by a 'secondary victim' and the second is by strategic enforcement.

\section{The Secondary Victim}

This theory is untested in the UK courts. A worker of any sex or ethnicity (including White), could complain that that working in a stratified imbalanced business is harmful to them. The issue is locus standi. A similar argument was advanced successfully in the US Supreme Court in Trafficante $v$ Metropolitan Life, ${ }^{37}$ where a White tenant (among others) was held to have standing to sue his landlord for (unlawfully) discriminating against prospective Black tenants. ${ }^{38}$ The claimants' harm was characterised thus:

'(1) they had lost the social benefits of living in an integrated community; (2) they had missed business and professional advantages which would have accrued if they had lived with members of minority groups; (3) they had suffered embarrassment and economic damage in social, business, and professional activities from being "stigmatized" as residents of a "White ghetto.", 39

If one exchanges 'living' and 'residents' for 'working' and 'workers' these 'harms' transfer readily to the employment context. Accordingly, in EEOC v Bailey, ${ }^{40}$ the US Sixth Circuit held that a White woman could sue her employer where its discriminatory policies meant she worked in an environment absent of Black workers and 'interracial association'. However, more recently, in Thompson $v$ NA Stainless, ${ }^{41}$ the Supreme Court refused to transpose wholesale Trafficante to the employment sphere. ${ }^{42}$ The Court held that the complainant's grievance must fall within the 'zone of interests sought to be protected by the statutory provision whose violation forms the legal basis for his complaint' and that there is no interest 'if the plaintiff's interests are so marginally related to or inconsistent with the purposes implicit in the statute that it cannot reasonably be assumed that Congress intended to permit the suit. ${ }^{43}$ The Court made no mention of Bailey, and of course, did not overrule Trafficante, as that claim was brought under a different statute. And so, the question remains open. One would suppose a workplace stratified along racial and/or gender classes would fall within the purpose of any anti-discrimination statute covering employment.

For the UK, the legal sources differ in principle. The US cases centre on the Constitutional 'standing' to sue. In the UK, for the present purpose, the standing to sue can be traced to the definitions of indirect discrimination for the field of employment in the Equality Act 2010.

\footnotetext{
37409 US 205 (1972), approved

${ }^{38}$ Title VIII of the Fair Housing Act 1968, 42 U.S.C. $§ 3610$ (a).

${ }^{39}$ Ibid, p.208.

40563 F 2d 439 (1977), p.452.

${ }^{41} 131$ S. Ct. 863 (2011).

${ }^{42}$ That is, Title VII of the Civil Rights Act 1964.

${ }^{43}$ Ibid, p.870.
} 
For this, the claimant must show that he or she was 'disadvantaged' by the discriminatory practice. This applies to existing employees thus:

'39 (2) An employer (A) must not discriminate against an employee of A's (B)--

... (d) by subjecting B to any other detriment.'

Assuming the deprivation of 'interracial association' is considered a 'detriment' (and a 'disadvantage' for s.19), ${ }^{44}$ the problem here is that the victim of the indirect discrimination (here, a member of the disadvantaged group, who was disadvantaged) has to be the same person who suffers the detriment (the deprivation of 'interracial association'), which of course is not the case. ${ }^{45}$ The only solution to this matter is to hold that the 'advantaged group' (e.g. Whites/men because they are more likely to be referred) is, for this purpose, the disadvantaged group. On exactly the same facts, both advantaged and disadvantaged workers could bring mirror-image challenges to the referral scheme. This is not as illogical as it may appear. Each group is suffering a different disadvantage, albeit, caused by the same practice. The respective disadvantages become more distinguishable when one considers that most principal victims are non-workers. Further, the secondary victim's claim is dependent on the principal discrimination being established. But this is not the case the other way round: to succeed, a primary victim does not require a white worker to be disadvantaged by the scheme. Finally, it accords with the policy of the legislation, which should not be a passive observer of workplaces stratified on gender or ethnic grounds.

\section{Strategic Enforcement - Equality and Human Rights Commission (EHRC)}

The Equality Act 2006 established the Commission and states that its duties specific to 'equality and diversity' are that the Commission 'shall' (a) promote understanding of the importance of equality and diversity, (b) encourage good practice in relation to equality and diversity, (c) promote equality of opportunity, (d) promote awareness and understanding of rights under the equality Act 2010, (e) enforce the Equality Act 2010, (f) work towards the elimination of unlawful discrimination and $(\mathrm{g})$ harassment. ${ }^{46}$ In addition, the Commission 'shall' promote and encourage 'understanding of the importance of good relations' and 'good practice in relation to relations' between members of different groups, and between members of groups and others. 'Groups' can be defined by age, disability, gender, gender reassignment, race, religion or belief, and sexual orientation. ${ }^{47}$ Its other specific duty is to promote human rights. ${ }^{48}$

${ }^{44}$ In Shamoon v Chief Constable of the Royal Ulster Constabulary [2003] I.C.R. 337, [35], the House of Lords stated the question was: 'Is the treatment of such a kind that a reasonable worker would or might take the view that in all the circumstances it was to his detriment?' It was not necessary to demonstrate some physical or economic consequence. Presumably, a similarly generous view would be taken towards 'disadvantage' for EA 2010, s.19.

${ }^{45}$ The parent Directives are similarly restrictive, providing that remedies must be 'available to all persons who consider themselves wronged by failure to apply the principle of equal treatment to them...' (emphasis supplied): Race Directive 2000/43, Art.7; Framework Directive 2000/74/EC, Art.9; Recast Directive 2006/54, Art.17

${ }^{46}$ EA 2006, s 8.

${ }^{47}$ EA 2006, s.10.

${ }^{48}$ EA 2006, s.9. 
The Commission has the power to issue Codes of Practice, ${ }^{49}$ conduct formal Inquiries and Investigations, enforce the Equality Act 2010 and in some cases EU discrimination law, ${ }^{50}$ and provide legal assistance to individuals. ${ }^{51}$ For these purposes, and the discussion below, an 'unlawful act' is an act contrary to the Equality Act 2010. ${ }^{52}$

\section{(a) Inquires and Investigations}

The Act provides the Commission with two forms of investigatory power: Inquires and Investigations. Inquiries are less serious and cannot, in themselves, lead to legal action by the Commission. By contrast, Investigations can have legal consequences.

Under EA 2006, s.16, the Commission can launch an Inquiry simply in pursuit of its duties. 'These could be thematic (for example into the causes of unequal outcomes), sectoral* (looking at inequality in, for example, the uptake of health screening services or at the employment of disabled people in particular sectors, e.g. the retail sector), or relate to one or more named parties. ${ }^{53}$ A 'named party' includes individuals, companies and organisations. Before the Inquiry, the Commission must publish its Terms of Reference. ${ }^{54}$ Afterwards, it may publish a report, but it cannot state or imply that a person has committed an unlawful act, unless it relates to human rights (even if this has implications under the Equality Act 2010). 55

If, during the Inquiry, the Commission suspects that person has committed an unlawful act, the Inquiry must not pursue that suspicion. Instead, the Commission may pursue it using an Investigation.

The Equality Act 2006, s.20, provides for Investigations, which involve formal and intrusive scrutiny of a named person, with potential legal consequences. Three possible triggers allow the Commission to embark on an Investigation. The first is where the Commission has a suspicion that a named person has committed an unlawful act. Under the previous regime the House of Lords held that this suspicion had to be a reasonable one (i.e. objective, not subjective) as a matter of public law principle. ${ }^{56}$ The White Paper suggested 'Suspicion that unlawful acts may have occurred could be formed by reports to the EHRC from victims of discrimination or harassment, by reports from third parties, or from cases ruled on by courts or tribunals. ${ }^{57}$ The Act itself suggests that the suspicion may be based on the results of, or a

\footnotetext{
${ }^{49}$ EA 2006, s 14.

${ }^{50}$ EA 2006, s 25.

${ }^{51}$ EA 2006, s 28.

52 Except for (a) socio-economic inequalities public sector duty (s.1); (b) public sector equality duties (ss.149, 153 or 154); (c) disabled persons: transport (Part 12); or (d) disability: improvements to let dwelling houses (s.90): EA 2006, s.34.

53 Explanatory Notes to the Equality Act 2006, para.56. Available at < www.legislation.gov.uk/ukpga/2006/3/notes/contents > accessed 28 July 2012.

${ }^{54}$ EA 2006, Sch.2, para.2.

${ }^{55}$ EA 2006, s.16(3) and (4).

${ }^{56}$ Re Prestige Group plc [1984] ICR 473 (HL).

57 White Paper, "Fairness For All: A New Commission for Equality and Human Rights", 2004, URN 04/1072, London: TSO, para.4.25.
} 
matter arising during the course of, an Inquiry under s.16. ${ }^{58}$ The Commission must draw up and publish terms of reference for the Investigation, and these must accord with its suspicion. ${ }^{59}$

The second and third possibilities for a named Investigation are where the Commission decides to ascertain if a person has complied with a requirement imposed by an Unlawful Act Notice, or with an undertaking given under a statutory Binding Agreement ${ }^{60}$ (see both below).

\section{(b) Unlawful Act Notices}

If, following an Investigation, the Commission concludes that unlawful discrimination has taken place, it may serve a notice on the named person requiring the discrimination to stop. This may also require the person to draft an action plan designed to avoid repetition or continuation of the unlawful act, which for a period of five years the Commission may monitor and enforce. Named persons subject to an Unlawful Act Notice may appeal within six weeks to an employment tribunal if the allegations fall within its jurisdiction, or to a county court or sheriff for any other acts. ${ }^{61}$

\section{(c) Binding Agreements}

Section 23 of the Equality 2006 allows the Commission to enter an Agreement with a person who undertakes to refrain from committing any discrimination and to take, (or refrain from taking) any specified act, including drafting an action plan. In exchange, the Commission promises not to pursue an Investigation nor issue an Unlawful Act Notice. The trigger for this power is where the Commission 'thinks' unlawful discrimination has been committed by the person. ${ }^{62}$ The Explanatory Notes (83) to the Equality Act 2006 assume that this means 'reason to suspect'. 63

The Agreement itself is enforceable. Where the Commission 'thinks' that a party to an Agreement has failed to comply, or is likely not to comply, with the Agreement, it may apply to a county court or sheriff for an order of compliance or for the person to take 'such other action as the court of sheriff may specify'. ${ }^{6}$

\section{(d) Application for Injunction}

If the Commission 'thinks' that a person is likely to commit an unlawful act, it may apply to the county court (or sheriff) for an injunction (or interdict) restraining the person from committing the act. ${ }^{65}$

\footnotetext{
${ }^{58}$ EA 2006, s.20(3).

${ }^{59}$ This was established under the original regime in Hillingdon London BC v CRE [1982] AC 779 (HL).

${ }^{60}$ EA 2006, s.20(1)(b) and (c).

${ }^{61}$ EA 2006, ss.21-22.

${ }^{62}$ EA 2006, s.23(2).

${ }^{63}$ Available at < www.legislation.gov.uk/ukpga/2006/3/notes/contents $>$.

${ }^{64}$ EA 2006, s.24(2) and (3).

${ }^{65}$ EA 2006, s.24(1).
} 


\section{(e) Enforcement}

Section 24A of the Equality Act 2006 provides that the Commission can use its powers set out above (Investigations, Unlawful Act Notices, Binding Agreements, and Injunctions) whether or not it 'knows or suspects that a person has been or may be affected by the unlawful act or application. ${ }^{66}$ This section was inserted by the Equality Act $2010,{ }^{67}$ and it replaces the Commission's previous powers which were more limited, regarding, for instance, advertisements and discriminatory practices. This means that even where there is no victim willing to take a stand, the Commission may still use its enforcement powers against any single employer. ${ }^{68}$

All this suggests that a stratified workplace is well within the remit of the Commission's specific duties, and it has a range of inquisitorial, investigative, and enforcement powers to address the problem. ${ }^{69}$

\section{Remedies}

The remedies for strategic enforcement are outlined above. They are adequate to force the abolition, or amendment, of a discriminatory scheme. But one might suppose that an individual suing an employer, especially a large employer, is unlikely to make much of an impact of the operation of the scheme, save for the deterrent factor. An employer may settle for damages, which in many of these cases would be appropriately discounted because the claimant's loss was only a loss of a chance ${ }^{70}$ of getting the job, rather than an outright discriminatory rejection. However, the Equality Act 2010 introduced a new power for tribunals. By s.124, EA 2010, Employment tribunals may make a recommendation, ${ }^{71}$ which can require:

'that within a specified period the respondent takes specified steps for the purpose of obviating or reducing the adverse effect of any matter to which the proceedings relate-

\footnotetext{
${ }^{66}$ EA 2006, s.24A(2).

${ }^{67}$ Inserted by EA 2010, Sch.26, para.68. (Originally by para.13; sch.26 has since been restructured: SI 2010/2279.)

${ }^{68}$ Equality Act 2006, s.24A(2).

${ }^{69}$ A search of the EHRC database finds no reference to employee referral schemes. The Commission has attacked word-of-mouth hiring in the construction industry for excluding ethnic minorities: 'Race Discrimination in the Construction Industry. Inquiry Report' (EHRC, 2009) ISBN 978184206187 9, pp.55-58 < http://www.equalityhumanrights.com/legal-andpolicy/inquiries-and-assessments/inquiry-into-race-in-the-construction-industry/inquiry-

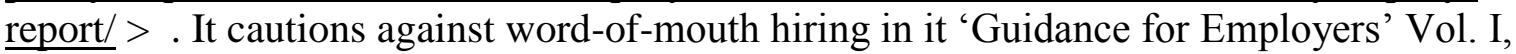
ISBN: 978010850973 5, p.20<

http://www.equalityhumanrights.com/publications/guidance-and-good-practicepublications/guidance-and-good-practice-for-employers/ > both accessed 30 July 2012.See also beyond employment, Handsworth Horticultural Institute Ltd v CRE (unreported) Birmingham County Court; see "Ruled Out", F Invest 1992, ISBN 185442 0887, (all-White social club in area of just $40 \%$ White population required that new members were sponsored by two members and approved by committee).

${ }^{70}$ See e.g. Chagger v Abbey National [2010] I.C.R. (CA), [57].

${ }^{71}$ EA 2010, s.124(2)(c).
} 
(a) on the complainant;

(b) on any other person, 72

If the employer fails to comply with the recommendation, the tribunal may order compensation. ${ }^{73}$

Paragraph (a) replicates the traditional individualistic basis of the discrimination legislation. ${ }^{74}$ It is limited to making a recommendation affecting the claimant, but not those in the same position. But paragraph (b) is new, and permits the recommendation to apply to 'any other person' affected by matters in the proceedings. This brings the legislation into line with the Northern Ireland ${ }^{75}$ and the United States. ${ }^{76}$ For paragraph (b), the Explanatory Notes (406) suggest a tribunal could recommend that an employer:

'introduces an equal opportunities policy;

ensures its harassment policy is more effectively implemented;

sets up a review panel to deal with equal opportunities and harassment/grievance procedures;

re-trains staff; or

makes public the selection criteria used for transfer or promotion of staff.'

This power enables tribunals to address the challenged scheme, and not just its effects on the claimant before it. If the claimant has proven that the scheme indirectly discriminates against a protected group, then the obvious recommendation is that the scheme is scrapped or at least operated in a way that no longer can discriminate. For instance, it is complimented by advertising targeting the under-represented group. Another is that the workforce and recruitment are monitored for gender and ethnicity.

\section{Employee Referral Schemes and their Safeguards}

The survey revealed a range of schemes. The simplest scheme encouraged employees to introduce a 'friend' to the business. Most offer employees a sum of money if the person they introduce to the business is employed. But some do not. All schemes reviewed ran on the businesses' intranet, while some were publically viewable through the business' website. Some schemes only pay when the person has been employed for a certain length of time, typically six months. Other businesses found this too complicated, and paid a fixed sum upon the appointment. Some schemes offered graduated payments, depending on the grade of the person hired. These schemes have no other formal regulation.

\footnotetext{
72 EA 2010, s.124(3).

${ }^{73}$ EA 2010, s.124(7).

${ }^{74}$ For a notably broad recommendation under the old regime, see De Gaulle v Delambre [2011] Eq. L.R. 948 (EAT) (hire HR consultant and introduce equality policy to whole organisation).

${ }^{75}$ Fair Employment and Treatment Order, 1998, SI 1998/3162, art.39(1)(d).

${ }^{76}$ Civil Rights Act 1964, s.706(g)(1), USC $§ 2000 \mathrm{e}-5(\mathrm{~g})(1)$. This is the principal employment discrimination federal legislation.
} 
The survey also revealed a range of safeguards in use.

\section{(1) Conflict of interest safeguards}

\section{Withdrawal from decision-making role}

A basic 'conflict of interest' safeguard, prevents any decision-maker, typically anyone at board level, or on a short-listing or interview panel, from being able to refer. One scheme operated a hybrid system where if a hiring manager were named as the referrer, he or she would then be asked if the candidate is a family member or a good friend. If so, the manager would be withdrawn from any decision-making for the particular case.

\section{No fee paid}

In some schemes, the referrer would not be paid a fee. But these people were 'actively encouraged' to refer because it was in their interest to refer people for their department. Their benefits are a) helping a 'friend' and/or b) helping their department improve (on the assumption they have found the best candidate), and so enhancing their own career prospects.

Of course, these 'plusses' for the referrer still leave scope for bias, where, say, a person on the interview panel has referred. The safeguard against bias here is the short-listing, which can be done by the recruitment team, who have the power to prevent a referred, but unsuitable, candidate from reaching the interview stage. Presumably, this safeguard can operate in reverse, where a person in the recruitment team refers. Here, the safeguard against bias should be at the interview stage, which should identify any unsuitable candidates.

\section{(2) Blind decision-making}

Even with conflict of interest safeguards, bias could operate for many reasons. For instance, where a person is withdrawn from the decision-making, a colleague may still be tempted to help the referred candidate out of loyalty or friendship to the (withdrawn) referrer, or indeed, to any colleague who has referred a candidate. Alternatively, a decision-maker (depending on range of responsibility and incentives) may be motivated to choose a referred candidate simply to save the business the agency fees. More sinisterly, there may be agreement to split the fee.

Accordingly, some schemes carry a more sophisticated guard against bias. Here, anyone in the decision-making process must be unaware that a candidate was referred. Thus, those short-listing and interviewing, consciously and subconsciously, treat the application as any other.

However, this can be difficult to implement thoroughly, especially in a small business. Decision-makers, such as the interview panel can become aware of the referred candidates through a number of means. For instance, some jobs require a competitive 'activity day', with successful candidates being further short-listed for interviews. A candidate could make it known to an instructor that he/she was referred, and this instructor may communicate (inadvertently) this to a decision-maker, say by an overheard conversation in the staff canteen or at a social event.

It might be that decision-makers become aware of those referred by default, where CV's normally land on the desk with an agency cover. This puts the onus to the recruitment team to 'clean' the application paperwork before it lands on the interviewer's desk. In turn, this 
exposes the recruitment team, who will be aware of the referral and are likely to do the shortlisting. Schemes guard against bias here by employing a mechanical exercise, simply sifting the applications for those that match the job specification and/or its 'skills set'. However, there remains scope for bias where a short-lister has discretion or has the autonomy simply to ditch rival applications, increasing the odds for the referred candidate.

\section{(3) Triangulation}

One scheme in the survey employed a mechanism to prevent any 'misuse' or 'loose ends'. The system was run online. So, a worker would go on to the intranet and refer someone. The system would then log the details of that referral (the referrer, candidate, and job title) and email them to the candidate with a prompt such as: ' $\mathrm{X}$ referred you for this role, if you would like to go ahead with your CV, use the following link to complete the application'. It is then up to that candidate to complete their application. Control of the application, and the data within it, remains with the candidate. If the candidate is hired, payment can be made to the referrer. As well giving control of the application to the candidate, 'triangulating' the referral (it is confirmed by the referrer, the employer, and the candidate) ensures that a referral fee is paid, and paid to the correct person.

This could prevent uncertainty where say: A worker sends in a CV, without the candidate's knowledge, as a 'favour'. The candidate is called for interview and appointed. The worker claims the referral fee, without the candidate and/or employer being aware of the referrer's involvement. The uncertainty would be increased where two workers referred the same candidate. This mechanism prevents these, and other, uncertainties.

\section{(4) Monitoring}

Some of the businesses interviewed, generally the larger ones, carried some form of monitoring. First, some broke down the applications by characteristics of gender, ethnicity, and disability. Not only does this give a picture of the applicant pool, but recording the successful applicants, over time, sketches a profile of the workforce. However, this information is collected from the voluntary section of the job application forms, and so will be incomplete and cannot be relied upon as definitive. Some monitored performance management and pay by gender, and were expanding this to other protected characteristics. This may help provide a profile of the workforce, and any gender-stratified imbalance. None made the small step to compare this with the labour market, ${ }^{77}$ and none of this was tied to the referral scheme.

Some monitored the recruitment rate via the referral scheme. This ranged from between 2-3 per cent through to 25 to 30 per cent of all recruits. This helped the business monitor factors such as recruitment costs, and the success of the scheme, and whether, say, it would benefit the business to increase the referral fees. None of this related to protected characteristics, however. For ethnicity and gender, none of the monitoring compared the application pool with the workforce profile, nor with other (non-referred) applicants, and none compared with the relevant labour market. Overall, as well as being incomplete, these data are scarcely used for any purpose, and certainly not for monitoring the referral scheme. Of course, the fact they are incomplete helps explain why they remain largely dormant.

\footnotetext{
${ }^{77}$ Using e.g. Neighbourhood Statistics. See below.
} 


\section{(5) Informal Safeguards}

Although these schemes carry little or no regulation, there are informal safeguards against bias. The informal safeguards against bias lay in the integrity of the selection process. For instance, a panel may not allow an individual to favour or prefer any candidate than the best. This becomes stronger where no payments are made. Here the decision maker/referrer has no direct financial motive, although there may be indirect financial motivation (e.g. to appoint a household family member), or a purely personal motive (to help a friend). Without formal safeguards, much may rest on the formal/informal power of the referrer. He or she may be senior to the others on the panel, or wield some other less formal influence, or even be 'owed a favour' by a majority of the panel. Smaller businesses may be more vulnerable here, where any individual is more likely to hold larger portions of power. Of course, it is less likely that small businesses can afford the formal safeguards.

\section{(6) Equality Policies}

The larger businesses ensured that all staff in the decision-making process were given formal training in equality matters. This gave them a general awareness of how discrimination might arise beyond the obvious or 'hostile' discriminatory conduct. They also employed objective decision-making, rejecting candidates who did not meet the job specification and/or its skills set. Depending on the contents of the skills set, this plays an important role in eradicating discrimination. Smaller businesses carried an 'informal' equality policy, ${ }^{78}$ which manifested as an awareness of the protected characteristics in anti-discrimination law and an expressed desire not to discriminate. Beyond that, there was no expertise, either in equal opportunities or objective decision-making. They trusted their general knowledge. In one case, a Human Resource manager considered that an Asian managing director was evidence that the business did not discriminate.

\section{Analysis of Safeguards}

The notable feature to all the safeguards is that they were not designed to guard against discrimination in the referral schemes. This is unsurprising as none of the businesses surveyed had an awareness of their potential to discriminate. The safeguards, especially objective decision-making, can of course prevent some discrimination, although its effectiveness would normally diminish with lesser skilled jobs. Moreover, for the present purpose, they do not address the issue of a distorted, or unbalanced pool of applicants. The best monitoring comes closest to this, and if fully realised and connected to relevant labour market figures, it would be the most effective alert method.

The incidental effectiveness against discrimination of the other safeguards may be borne out by the facts, and a small firm, with an ostensively mixed workforce, may be less vulnerable here simply because it would be harder to establish significant statistics, as shown in Case 2, below. And nepotism and subjective hiring are not unlawful in themselves. ${ }^{79}$ But the absence

\footnotetext{
${ }_{78}^{78}$ See above (6) Equality Policies.

${ }^{79}$ In Coker v Lord Chancellor [2002] I.C.R. 321, [40], the Court of Appeal went further and suggested that appointing from a small circle of friends was not discriminatory.
} 
of a formal and credible equality policy leaves businesses vulnerable to other discrimination claims, where an informal policy may not stand up to scrutiny. ${ }^{80}$

\section{Analysis - The Case Studies}

The businesses surveyed ranged in size from employing 20 or so to a few hundred, and up to 12,000 workers. The case studies reflect this, based on small, medium, and large businesses. ${ }^{81}$

The following (fictitious) cases are based in Luton, Bedfordshire. The surrounding circumstances to real life cases vary enormously, and would be of little interest to anyone bar that particular case. So these case studies are deliberately simplistic, to illustrate at least the legal starting points for analysing any particular scheme.

The headline population figures for Luton are as follows:

\begin{tabular}{l|ccccc|} 
Luton $^{82}$ & Total & White & Asian & Black & Others \\
\hline Working Age & 122,900 & $82,100(66 \%)$ & $24,100(20 \%)$ & $10,000(8 \%)$ & $6,700(5 \%)$
\end{tabular}

The 'working age' figures are the closest indicator of the general labour market in the district.

\section{Case 1 - Small}

80 Employers must produce 'cogent' evidence to rebut a prima facie case of direct discrimination: Igen (formally Leeds Careers Guidance) $v$ Wong [2005] I.C.R. 931, annex to judgment, para.13, and EA 2010, s.136. Also note that in the US it has been held that 'Statistics showing a racial or ethnic imbalance are probative ... only because such imbalance is often a telltale sign of purposeful discrimination ... it is ordinarily expected that nondiscriminatory hiring practices will in time result in a workforce more or less representative...': International Brotherhood of Teamsters v US 431 US 324, 329, n.20 (Sup Ct 1977).

${ }^{81}$ The Companies Act 2006 categorises 'small' as having no more than 50 employees, (s 382(3)) and 'medium' having no more than 250 (s.465(3)). The category of micro, small and medium-sized enterprises (SMEs) is made up of enterprises which employ fewer than 250 persons and which have an annual turnover not exceeding 50 million euro, and/or an annual balance sheet total not exceeding 43 million euro.' Extract of Article 2 of the Annex of Recommendation 2003/361/EC.

82 Luton's local authority area. As at June 2009. By numbers: < http://neighbourhood.statistics.gov.uk/dissemination/LeadTableView.do? $\mathrm{a}=7 \& \mathrm{~b}=276843 \& \mathrm{c}=$

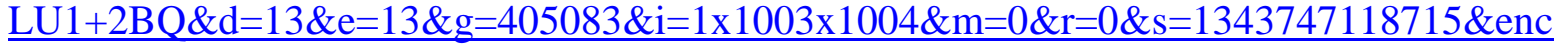
$=1 \&$ dsFamilyId=1809 $>$ By percentages: < http://neighbourhood.statistics.gov.uk/dissemination/LeadTableView.do?a=7\&b=276843\&c= LU1+2BQ\&d=13\&e=13\&g=405083\&i=1x1003x1004\&m=0\&r=0\&s=1343747118715\&enc $=1 \&$ dsFamilyId=1812 $>$ accessed 31 July 2012 . 
A small firm, based in Luton, Bedfordshire, employs 46 people, at 3 levels, 15 at each level: unskilled, semi-skilled, and skilled. At the unskilled level, 14 of the 15 are Asian, whilst one is Black. For semi-skilled and skilled, the balance is 13 White and 2 Asian. The owner and managing director is Asian. The optimal number of workers for each the three job levels (i.e. excluding the M-D) is given in the square brackets.

\begin{tabular}{l|cccc} 
Case 1 & Total & White & Asian & Black \\
\hline Working Age & 122,900 & $82,100(66 \%)$ & $24,100(20 \%)$ & $10,000(8 \%)$ \\
& & {$[10]$} & {$[3]$} & {$[1]$} \\
Unskilled & 15 & -- & $14(93 \%)$ & $1(7 \%)$ \\
Semi-skilled & 15 & $13(86 \%)$ & $2(13 \%)$ & - \\
Skilled & 15 & $13(86 \%)$ & $2(13 \%)$ & - \\
M-D & 1 & - & 1 & -
\end{tabular}

The firm operates a referral scheme open to workers at all levels. It pays a flat fee of $£ 50$ on appointment. It has no safeguards, apart from an informal equality policy. There is no monitoring.

A survey of the existing staff reveals that the referral scheme accounted for the all the unskilled workers, and about half (7/15) of the semi-skilled and skilled ones; in every case, the worker made a referral to a job at his or her level, and in every case, the worker and referred person were from the same ethnic group.

Overall, this workplace appears unbalanced, with ethnic minorities doing the unskilled jobs, and just four 'token' Asians in the better jobs. However, discrimination law may not be able to achieve much here. First, the only significant disparity is the over-representation of minorities in the unskilled jobs. (As the recruitment rate here is one hundred per cent, proving causation would be straightforward.) This means that the most likely legal action here would be by a white person, alleging that the referral scheme excluded him. It is less likely that the EHRC would bear down on this firm to employ more Whites at this level, at the expense of Asians. The third possibility here is that 'secondary victim' may sue. ${ }^{83}$

Should a claim be brought, on the face of things, the employer has little to objectively justify the practice. The informal equality policy appears at best to have screened out conscious direct discrimination, but nothing more. There is no conscious effort at balanced recruitment, such as advertising across a balanced range districts/mediums for the area. Further, if the workforce profiles were monitored the cause may have been identified long before they became this unbalanced. The ethnicity of the managing director clearly has made little, if any, difference.

That said, on all three possibilities, although the claim may be sound technically, it would carry less merit on policy grounds. Such a claim would be unlikely.

${ }^{83}$ See above, under 'Who sues?'. 
On these small numbers, it is unlikely that the disparity within the semi-skilled jobs is significant. Here, the ideal representation of Asians would be 3 ( 20 per cent) persons, and so if just two more Asians replaced two White workers, Asians would be over-represented at this level. With this, a referral scheme could begin to favour Asians. The same can be said for the skilled jobs, and of course, Black profile, where the employment of two Blacks at either level would switch that profile to advantageous.

\section{Case 2 - Small}

The facts are exactly as Case 1 (above), save that the unskilled profiles differ. Here, 8 are White, 5 are Asian, and 2 are Black.

\begin{tabular}{l|cccc|} 
Case 2 & Total & White & Asian & Black \\
\hline Working Age & 122,900 & $82,100(66 \%)$ & $24,100(20 \%)$ & $10,000(8 \%)$ \\
& & {$[10]$} & {$[3]$} & {$[1]$} \\
Unskilled & 15 & $8(53 \%)$ & $5(33 \%)$ & $2(13 \%)$ \\
Semi-skilled & 15 & $13(86 \%)$ & $2(13 \%)$ & - \\
Skilled & 15 & $13(86 \%)$ & $2(13 \%)$ & - \\
M-D & 1 & - & 1 & -
\end{tabular}

This workplace still appears unbalanced, with Asians and Blacks over-represented in the unskilled department, and under-represented in the better jobs. But now, even the unskilled profile is not significantly unbalanced. Although Asians occupy the unskilled jobs at over one and a half times the regional proportion, a change of just 3 workers from Asian to White or Black would reduce this to less than the regional proportion. Again, if just one black worker were replaced, Blacks would be slightly under-represented (6.6 per cent).

The suggestion of imbalance from this snapshot may be misleading as well if there were a high staff turnover, with, say, the various groups vacillating between over- and underrepresentation. As such, it would be most unlikely that referral scheme could be shown to be inherently discriminatory against any protected group.

\section{Case 3 - Medium}

This is the same as Case 2, save for the larger scale. Here, the business employs 450 people, at 3 levels, 150 at each level: unskilled, semi-skilled, and skilled. At the unskilled level, 80 are White, 50 Asian, and 20 Black. For semi-skilled and skilled, the balance is 130 White, 20 Asian.

All other things are equal, such as the profile of those drawn from the alternative recruitment (e.g. advertising/agency), and the selection process.

\begin{tabular}{l|cccc} 
Case 3 - & Total & White & Asian & Black \\
\hline Working Age & 122,900 & $82,100(66 \%)$ & $24,100(20 \%)$ & $10,000(8 \%)$ \\
& & {$[99]$} & {$[30]$} & {$[12]$} \\
\multirow{2}{*}{ Unskilled } & 150 & $80(53 \%)$ & $50(33 \%)$ & $20(13 \%)$ \\
\cline { 2 - 5 } & & &
\end{tabular}


Semi-skilled

Skilled

\begin{tabular}{|llll|}
\hline 150 & $130(86 \%)$ & $20(13 \%)$ & - \\
150 & $130(86 \%)$ & $20(13 \%)$ & - \\
\hline
\end{tabular}

This workplace still appears unbalanced, with Asians and Blacks over-represented in the unskilled department, and under-represented in the better jobs.

For the unskilled jobs, it would take a change of 20 workers from Asian to White or Black to obtain the optimal number (30). As such, this would appear to be a significant disparity, and coupled with the 100 per cent recruitment rate as this level, the scheme would seem to be the cause. Similarly, it would take the replacement of 12 Black workers to normalise the proportions.

For the semi-skilled jobs, the optimal representation of Asians would be 30 persons, and so it would take the recruitment of 10 more Asians in place of others to normalise the proportions. The same can be said for the skilled jobs, and of course, Black profile, where it would take the employment of 12. This gets as far as showing the workplace disparity is significant. But causation might be more difficult to prove, as the recruitment rate is only 50 per cent.

Staying with the class of semi-skilled, for each white worker there are $632^{84}$ Whites in the local labour market, whilst for each Asian worker there are $1205 .{ }^{85}$ In other words, a white person has roughly twice as much chance of knowing someone in that job than an Asian person. Now, these odds may reduce as the scheme's recruitment rate reduces. Eventually, the odds will close enough to be insignificant. Bearing in mind the unbalanced profile of the workforce, this does not necessarily mean that there is no discrimination in recruitment. It just helps to identify the cause. If, as assumed in this example, all other things were neutral, then the scheme appears to be discriminating more than one would expect. On the other hand, if the alternative pool were similarly unbalanced, then the advertising may be at fault, say by advertising predominantly to White audiences. It might be that the selection process is flawed. If there were multiple causes of a significant unbalanced workplace, and each cause itself is insignificant, policy dictates that such an employer should not escape liability. And so, where it cannot be shown that any particular practice is causing a significant disparity, a case ought to be established on a combination of causes. ${ }^{86}$

\section{Case 4 - Large}

The importance of scale is illustrated by projecting Case 2 (above) to a size 100-times larger. Here, the proportions are exactly as Case 2. This case differs in scale, and carries some more sophisticated safeguards.

\footnotetext{
${ }^{84} 82,100 / 130$.

${ }^{85} 24,100 / 20$.

${ }^{86}$ It was a subject of controversy in the US, where a bare majority of the Supreme Court in Wards Cove v Atonio 490 US 642 (1989) held that it was necessary to isolate each specific employment practice and show it caused a disparity. Congress acted to clarify the law and passed section 105 of the Civil Rights Act 1991, which endorsed Wards Cove by providing that complainants must show that "each particular challenged employment practice causes a disparate impact..." but qualified it by stating that where the decision making process is not capable of separation for analysis, it may be treated as one employment practice.
} 
This company employs 4,500 people, at 3 levels, 1,500 at each level: unskilled, semi-skilled, and skilled. At the unskilled level, 800 are White, 500 Asian, and 200 Black. For semi-skilled and skilled, the balance is 1300 White, 200 Asian.

\begin{tabular}{l|cccc|} 
Case 4 Large & Total & White & Asian & Black \\
\hline Working Age & 122,900 & $82,100(66 \%)$ & $24,100(20 \%)$ & $10,000(8 \%)$ \\
& & {$[990]$} & {$[300]$} & {$[120]$} \\
Unskilled & 1500 & $800(53 \%)$ & $500(33 \%)$ & $200(13 \%)$ \\
Semi-skilled & 1500 & $1300(86 \%)$ & $200(13 \%)$ & - \\
Skilled & 1500 & $1300(86 \%)$ & $200(13 \%)$ & - \\
\hline
\end{tabular}

The company operates a referral scheme open to workers at all levels. It pays a flat fee of $£ 50$ on appointment. Its recruitment staff are trained in equality matters, interviewing, and objective decision-making. Optional diversity forms are issued with each application pack. The resulting figures are collected but not monitored.

The company records all referrals, and the evidence is that the referral scheme accounted for the all the unskilled workers, and about half of the semi-skilled and skilled ones. In every case, the worker made a referral to a job at his or her level.

Although the proportions remain the same as the Case 2 (above), the disparities are more likely to be significant. For example, the 'optimal' number of Asian workers is 300 per level. At the unskilled level, it would take a large shift in numbers to 'balance' the profile. For the semi-skilled or the skilled jobs, the disparity starts to look 'considerable', with another 100 workers required to balance each the profile, even though each remains just seven per cent short of the regional profile. This would be especially so if this disparity persisted over a several years. ${ }^{87}$

Proving causation is straightforward in the case of the unskilled workers, as the recruitment rate is 100 per cent. However, things become more nuanced for the better jobs. At 50 per cent, the scheme remains a significant cause in this Case. But is shows that again, much depends on scale. If the numbers involved were much fewer, a 50 per cent recruitment rate might not be enough to show causation. Of course, as noted above, as the recruitment rate drops, arguments that the scheme is not the cause simply moves the focus of suspicion to another part of the hiring process.

\section{Possible Alternative Explanations of the Unbalanced Workforce}

\section{Claimant's group less qualified.}

${ }^{87}$ Seymour-Smith Case C-167/97, [1999] I.C.R. 447 (ECJ), [61]: A prima facie case can be established where "the statistical evidence revealed a lesser but persistent and relatively constant disparity over a long period." 
Of course, it is likely in these Cases that the better jobs carry formal qualification/skills set requirements, and a rigorous application of these requirements is the cause of the disparity. Stood alone, this simply implicates the job requirements. The employer would have to go further and argue that an unbalanced workforce is due to the unbalanced qualification profile of the applicants. The employer faces two problems here. First, if the employer is selecting from an unbalanced pool in the first place, it would have to go a long way to rebut the inference that the cause is the referral scheme. After all, a perfectly objective selection criterion will simply replicate the pool from which it draws. The presumption is that Whites, Blacks, and Asians, have roughly similar educational profiles, with females slightly but significantly outperforming males. ${ }^{88}$ The employer's argument may increase in credibility where specialist qualifications are required. Here, the employer may be able to show that the claimant's group was under-represented in, say, science, plumbing, or catering, qualifications (and so on), and that these roughly corresponded to the workforce. This would show the cause of the unbalanced workforce is job requirement and the disproportionately low number of qualified persons from the claimant's group. Of course, this exposes the job requirement to litigation. Thus, the second problem for the employer would be would be showing that the requirement could be objectively justified as being strictly necessary for the job. It may be, for instance, that a business carrying out large building contracts requires only one officially registered tradesperson per team to authenticate the work.

\section{Multi-stage recruitment process favouring minorities or women}

Generally, as jobs become more skilled, there will be more stages in the recruitment process. An employer may be able to argue that the process overall does not discriminate. Take, for instance, a two-stage process. First, the pool of candidates is gathered by the referral scheme. Second, the candidates sit an entrance exam. Those with the best scores are appointed. It might be that the pool is unbalanced, disfavouring Asians. But then Asians outperform others in the exam. The overall effect is neutral (in time, this is likely to balance the particular workforce). The employer here may argue that its selection procedure does not discriminate.

This argument has not been tested in the UK courts, but has been rejected in the United States ${ }^{89}$ and is likely to fail here as well. The particular disadvantage is that Asians are

\footnotetext{
${ }^{88}$ See n.14. For educational qualifications broken down by gender and ethnicity. see e.g. for Luton: http://www.neighbourhood.statistics.gov.uk/dissemination/LeadDatasetList.do?a=7\&b=3567 $704 \& \mathrm{c}=\mathrm{CO} 5+0 \mathrm{PD} \& \mathrm{~d}=14 \& \mathrm{e}=5 \& \mathrm{f}=41 \& \mathrm{~g}=404618 \& \mathrm{i}=1 \times 3 \times 1004 \times 1005 \& \mathrm{l}=81 \& \mathrm{o}=1 \& \mathrm{~m}=0 \& \mathrm{r}=$ $0 \& s=1237047417546 \&$ enc $=1>$. National statistics can be found here: < http://www.education.gov.uk/rsgateway/DB/SFR/s000986/index.shtml > both accessed 31 July 2012.

${ }^{89}$ Connecticut $v$ Teal 457 US 440, p.452 (1982 Sup Ct). A two-stage entrance test was used. The first screened out 46 per cent of the Black applicants, but only 20 per cent of the White ones. However, 22.9 per cent of the initial Black applicants passed the second test, compared to just 13.5 per cent for the White applicants. The employer argued a "bottom line" defence, that ultimately, the testing had not adversely affected the Black applicants. The US Supreme Court rejected this argument, and held that the focus should be on the initial screening test (which was discriminatory). See also New York Transit Authority v Beazer, 440 U.S. 568, p.584 (1979 Sup Ct): 'A prima facie violation of the Act may be established by statistical evidence showing that an employment practice has the effect of denying members of one race equal access to employment opportunities' (emphasis supplied).
} 
disproportionately excluded from the job opportunity. Of course, if the selection pool were neutral, even more Asians would be selected. This merely exposes the entrance exam as suspect (the potential discrimination here is against Whites and others, who might dispute the validity of the exam).

\section{The Defence of Objective Justification}

Once the claimant has established a prima facie case, the burden shifts to the defendant to "objectively justify" the provision, criterion or practice. As noted above, the Equality Act 2010 requires the employer to show that the challenged practice is 'a proportionate means of achieving a legitimate aim' (s.19(2)(d)). This is a compressed interpretation of the parent EU law, which requires a legitimate aim, and that the means of achieving that aim are appropriate and necessary. ${ }^{90}$

\section{Examples of the Defence}

\section{Economic Reasons}

The European Court of Justice has sanctioned economic business reasons as a defence to indirect discrimination. In Jenkins $v$ Kingsgate (Clothing Productions) Ltd $^{91}{ }^{1}$ it held that lower pay (measured pro-rata) for (predominantly female) part-time workers could be justified by economic factors, which were in this case encouraging full-time work to achieve better utilisation of the employer's machinery and to discourage absenteeism. An 'economic reason' was also approved in Bilka, ${ }^{92}$ where a department store wanted to discourage parttime work (by excluding part-time workers from its pension scheme), because part-time workers generally refuse to work late afternoons and Saturdays. Of course, the defence must be genuine, appropriate and necessary. In Cumbria CC v Dow (No 1) ${ }^{93}$ the EAT accepted that productivity bonuses for one (predominantly male) group of workers could justify a pay disparity, but as the bonus arrangements were no longer properly enforced and made no difference to productivity, there were not justifiable.

The chief reasons, it seems, for deploying referral schemes are either to save costs on expensive recruitment agency fees ${ }^{94}$ or to fill a skills gap by casting the recruitment net as far and wide as possible.

If casting the net as wide as possible is the goal, and the resulting pool is unbalanced, the goal has not been achieved, and a more appropriate method is required. Thus, although the aim may be legitimate, the method is not.

On costs, it may not be enough to show that the referral fee is less than an agency fee. For instance, one employer observed:

\footnotetext{
${ }^{90}$ See e.g. Bilka-Kaufhaus v Weber von Hartz Case 170/84, [1987] I.C.R. 110 (ECJ).

${ }^{91}$ Case 96/80, [1981] ECR 911,§ 12 (ECJ), applied by the EAT [1981] I.C.R. 715, esp. at pp. 723-724.

${ }_{92}$ Bilka-Kaufhaus $v$ Weber von Hartz Case 170/84, [1987] I.C.R. 110, [36] (ECJ).

93 [2008] I.R.L.R. 91 (EAT), [129]-[136].

94 See e.g. case study of Xansa in 'Recruitment, Retention and Turnover', Annual Survey Report 2006 CIPD (London 2006), 10.
} 
'[W] want to hire the best possible candidate for the role...[W]e look at what is the average length of the time of someone coming in and being placed via an agency. In excess of four years, when you take that agency fee and divide it by four years the cost is minimal. But the return on having someone really good doing that job far outweighs that particular cost.'

Thus, the employer must show that the cost-saving is genuine, appropriate, and necessary. At the same time, Tribunals must be careful not to interfere with genuine business judgments, and it would seem that as long as the cost-saving aim is not a sham (legitimate), shows a relationship to the scheme (appropriate), it should satisfy the first two elements of the defence. On 'necessity', much will turn on the amount of the saving in comparison to the degree of discrimination. Thus, a dramatic imbalance will not be justified by a relatively minor cost-saving.

There are other 'soft' advantages. The success of a scheme is a 'measure of "organisational commitment" in some high performing organisations' and candidates get a 'preview' or insight into the job. ${ }^{95}$ Some employers claim the benefits of better discipline, efficiency, and morale. These include: (a) the reputation of the person recommending the newcomer will predict that newcomer's quality; (b) the person introducing the newcomer will be responsible for ensuring their continued good behaviour, particularly in the case of younger recruits; (c) it is a contribution to a 'good' industrial relations climate; and (d) it is part of a 'family firm' ethos (33 per cent of line managers). ${ }^{96}$ On the same theme, one business reported morale as the 'key benefit': 'there's no better story than someone internally turning and saying, "look, I really enjoy working here and I think you would too"'.

Any of these reasons could be used by an employer defending an otherwise discriminatory referral scheme. A combination would strengthen the defence. Again, proportionality dictates that these reasons will weaken as the disparity becomes more serious. To take an extreme example, 'advantages' of morale would appear repugnant even, if being weighed against a near-segregated workplace.

\section{Testing and educational qualifications ${ }^{97}$}

This is not a direct defence to a discriminatory referral scheme, but the use of objective decision making based on formal qualifications may be deployed to explain the unbalanced

${ }^{95}$ C Evans, J Glover, Y Guerrier, C Wilson, 'Effective recruitment strategies and practices: addressing skills needs and gender diversity challenges in ITEC and related sectors' (2007) Equalitec 2007), p.11.

$<$ www.equalitec.org.uk/downloads/Effective_recruitment_strategies_and_practices.pdf $>$ accessed 25 June 2012

${ }^{96}$ R. Jenkins, 'Acceptability, Suitability and the Search for the Habituated Worker: How Ethnic Minorities and Women Lose Out', International Journal of Social Economics, (1993), Vol. 11 Iss: 7 pp. $64-76$.

97 See R. Wood, "Psychometrics should make assessment fairer". (1996) 67 EOR 27; M. Pearn, R. Kandola, and R. Mottram, Selection Tests and Sex Bias: the Impact of Selection Testing on the Employment Opportunities of Men and Women, 1987, Manchester: EOC; Towards Fair Selection: a Survey of Test Practice and Thirteen Case Studies, 1993, London: Commission for Racial Equality. 
workforce. An employer may show that that Whites (or men) pass formal entrance exams at a higher rate than, say, Asians (or women). There are two considerations here.

First, different success rates for protected groups is a sign that the test is flawed. Here, the employer could face a discrimination claim regarding the tests and would be put to proof that that the tests are genuine and proportionate indicator of job performance. Second, otherwise valid and relevant tests may be flawed simply because they are not updated regularly. As such, they might adversely affect a minority group, say recent immigrants, simply because white candidates are more familiar with the test through their links with the predominantly white workforce. Thus, although the test may be legitimate and appropriate as valid indicator of job performance, they are not necessary, because there exists a less discriminatory alternative (regular updating).

\section{Conclusion}

Safeguards associated with the schemes surveyed will do little to prevent discrimination. The key safeguard is monitoring. The benefit of this is that it can alert employers to all causes of discrimination in hiring, not just referral schemes. Further, it would normally prove relatively inexpensive.

Proper monitoring should compare the workforce profiles (at various levels) with the relevant labour market(s). This would be normally the employer's locality, for which statistics are easily available. It involves a simple survey of the staff (if the information is not held already), a calculation of the proportions with protected characteristics, and comparison with those proportions with the local (or appropriate) statistics. Where the catchment area is broader, say, for highly skilled, transient, specialised, or localised (e.g. oil rigs) jobs, this may prove more difficult. It might be that simple national statistics would suffice. Where the catchment area is narrower, say where formal educational qualifications are required, the spread of these generally is roughly equal, with females slightly better qualified. Again local and national statistics are available. Nonetheless, monitoring the profile and applicant pool should alert HR managers to any 'worrying' patterns, which be a symptom of hitherto unknown discriminatory practices.

Most schemes in the survey had a relatively low recruitment rate, normally no more than five per cent. So, where there is an unbalanced workforce, the scheme is unlikely to be the principal cause. But it could be, or at least be a contributory factor. This becomes more likely with bigger employers, as apparently minor disparities can become significant as the numbers grow. Here, a record of the pool of applicants by gender and ethnicity (ideally by all protected characteristics), and their success rate should reveal how far, if at all, the scheme is responsible. Employers should not attempt a short cut by hiring by quota. This is unlawful and is likely to be encounter litigation ${ }^{98}$ and adverse publicity. Proper monitoring is a good method of avoiding litigation, or at worst, defending it.

${ }^{98}$ In Jepson and Dyas-Elliott v The Labour Party [1996] IRLR 116 (IT), the Labour Party's policy of all-women short-lists for parliamentary candidates was held to be unlawful discrimination. The effect of the decision was reversed by dedicated legislation, providing a non-symmetrical exception to the equality principle SDA 1975, s 42A, inserted by the Sex Discrimination (Election Candidates) Act 2002, s.1. See now, EA 2010, s.104. 
The worrying legal aspect from a public policy perspective is the inadequacy of the law to address stratified 'bottom-heavy' workplaces, with minorities and/or women predominant in the low-pay/unskilled jobs. Here, there is little that individual litigation can achieve, save Whites/males suing to get more of the low-skill, low-pay jobs. The best approach here would seem to be strategic, by the Equality and Human Rights Commission, who can conduct inquiries and investigations into the whole organisation, and have wide range of enforcement powers.

The factors on which a prima facie case may rest are: the profile of the workforce, by department, and (less likely) overall; the size of the business/number of workers (for significant statistics); the recruitment rate of the scheme; changes in the ethnicity of the relevant labour market; length of time business in the locality; (justifiable) job requirements; and subjective/objective decision-making. 